$11-1-2012$

\title{
Do Sensory Ad Appeals Influence Brand Attitude?
}

\author{
Sung-Joon Yoon \\ Kyongggi University, sjyoon@kgu.ac.kr \\ Ji Eun Park \\ Cleveland State University, j.park16@csuohio.edu
}

Follow this and additional works at: https://engagedscholarship.csuohio.edu/bus_facpub

Part of the Advertising and Promotion Management Commons, Marketing Commons, and the Psychology Commons

How does access to this work benefit you? Let us know!

\section{Publisher's Statement}

NOTICE: this is the author's version of a work that was accepted for publication in the Journal of Business Research. Changes resulting from the publishing process, such as peer review, editing, corrections, structural formatting, and other quality control mechanisms may not be reflected in this document. Changes may have been made to this work since it was submitted for publication. A definitive version was subsequently published in Journal of Business Research, 11, 11, 01-01-2012, 10.1016/j.jbusres.2011.02.037

\section{Original Published Citation}

Yoon, S. \& Park, J. (2012). Do sensory ad appeals influence brand attitude? Journal of Business Research, 65(11), 1534-1542. doi: 10.1016/j.jbusres.2011.02.037

This Article is brought to you for free and open access by the Monte Ahuja College of Business at EngagedScholarship@CSU. It has been accepted for inclusion in Business Faculty Publications by an authorized administrator of EngagedScholarship@CSU. For more information, please contact library.es@csuohio.edu. 


\title{
Do sensory ad appeals influence brand attitude?
}

\author{
Sung-Joon Yoon ${ }^{\mathrm{a}, *}$, Ji Eun Park ${ }^{\mathrm{b}, 1}$ \\ a Department of Business Administration, Kyonggi University, Republic of Korea \\ ${ }^{\mathrm{b}}$ Cleveland State University, Nance College of Business Administration, Department of Marketing,1860 E. 18th Street, BU 449, Cleveland, OH 44115, USA
}

\section{Introduction}

Human senses are an incredible information collection system. Through them, we create and recreate images of ambient situations and, based on that information, intuitively and instantaneously process sensory information to make imminent decisions. Recently emerging behavioral economists have begun addressing this need for "sensory marketing," which emphasizes the sensory impressions that usually accompany optimal emotional responses to cause changes in purchasing behavior.

Traditional information processing in consumer behavior theories encompasses a broad range of stages. Consumers review and evaluate each piece of information (i.e. company, product, store, ads, etc.) through the stages of exposure, attention, and comprehension, arriving at a final judgment: purchase intention. A stimulus is detected in sensory registers and transmitted to short-term memory, where it is attended to and comprehended through the process of encoding, storage, and retrieval from long-term memory. In this perspective, it is important not only to understand the role of senses in information processing but also to develop new consumer decisionmaking models based on the senses by critically reexamining the cognition- or emotion-based models.

\footnotetext{
* Corresponding author at: Kyonggi University, Department of Business Administration, Seodaemoon-gu, Choongjongro 2ga, Seoul, Republic of Korea. Tel.: +822390 5135(office), +82102213 1223(mobile).

E-mail addresses: sjyoon@kgu.ac.kr (S.-J. Yoon), j.park16@csuohio.edu (J.E. Park).

${ }^{1}$ Tel.: +12166874787.
}

In traditional consumer decision-making processes, reasonable decisions and inferences are made based on the process of learn-feelact. However, a new sensory branding model based on intuitive and unconscious information processing proposes that consumers sense first, then feel or think, and act last. The understanding of how our senses work is especially important in branding. Making a sensory, emotional, and rational connection with consumers can stimulate their senses and appeal to them, thereby rendering marketing plans far more effective (Hill, 2003).

The link between sensory appeals and brand effectiveness has been demonstrated by the studies of Lindstrom (2005), who argued that each brand must incorporate sensory appeals specific to its product features. Lindstrom's pioneering research proposes a multisensory branding strategy that encompasses a consumer sensory experience. According to the results of focus group studies in thirteen countries and research on brand sense in global markets, each brand has a sensory profile related to at least one distinct and positive sensory characteristic. Some brands have several sensory characteristics simultaneously. For instance, CocaCola appeals to various senses through sight (its curvy bottle), touch (the feel of its cool package), hearing (the sound created when pouring), and taste (its invigorating flavor). Lindstrom (2005) also suggests that consumer brand loyalty results from sensory perceptions of superior brand experience, leadership, and clarity. In a study of nine different brands, sight had a significant relationship with brand leadership and clarity and played a supplementary role in the other functions. Taste, touch, and smell all enhanced brand loyalty through superior brand experience. In addition, all five senses have different levels of impact on loyalty, with taste exerting the greatest influence, followed by smell, 
sound, touch, and sight. The more sensory stimuli provided by a product, the greater the product's perceived value. Therefore, developing a branding strategy based on sensory experience has important implications in a consumer market characterized by individuals' emotions and experiences.

In light of these findings, the research presented here explores the mechanism in which sensory appeal affects brand attitude by employing both qualitative and quantitative methods to develop a sensory branding model. To date, research suggests that selfreferencing influences positive effect, which improves ad attitude (Chang, 2005), or affects mental simulation, which eventually enhances brand attitude (Escalas, 2004). Comparatively little research, however, explores the mediating effects of self-referencing on sensory preferences, viewing self-reference as a collateral construct to positive affect with consequent influences on evaluative judgments and attitudes toward brands. Rather, researchers have investigated positive affect as merely an antecedent or emotional linking pin to brand equity without concomitant consideration of the role of selfreferencing (Gurhan-Canlil and Ahluwalia, 1999; Kamp and Macinnis, 1995). Thus, our understanding of the roles of self-referencing and positive affect as dually conjoint mediators between sensory preference and brand attitude remains somewhat limited.

Another relatively poorly researched area of sensory effects in branding is that concerning the role of multisensory appeals of an ad's creative elements and the impact they may have on attitudes toward the brand. The literature discusses synaesthetics as a term to explain the synthetic mechanism of multi-senses (Cooper and Braithwaite, 2002; Lindstrom, 2005), but empirical applications of the concept in advertising studies are difficult to find. Yet another potentially important area warranting further investigation in connection with the sensory effects of ads is "creativity in advertising," which would strengthen both methodological and theoretical aspects of introducing creative approaches to ad effectiveness (O'Quin and Besemer, 1989; Heiser et al., 2008).

The research here consists of two parts. Study 1 proposes that consumers have a predisposed preference toward sensory clues featured in coffee ads that creates self-referencing when the sensory appeals are perceived as congruent with one's image. A consumer emotionally identifying with sensory stimuli elicits a positive affective response. The self-referencing and positive affect boost brand attitude. The study investigates whether self-referencing and positive affect in ads play a role in mediating between sensory preference and brand attitude. Further, it empirically tests for any difference in mediating effects depending on type of ad (copy or visual). Added to this objective is an exploration of the effects of multisensory appeals on brand attitude, with special attention to the presence of synaesthetic functionality among those appeals.

Study 2 presents a case approach to sensory perceptions of an established specialty coffee brand (The Coffee Bean \& Tea Leaf) by qualitatively eliciting the core sensory concepts through image-based techniques such as ZMET (Zaltman Metaphor Elicitation Technique, developed by Zaltman and Coulter, 1995). Specifically, the research aims to elicit metaphysical thoughts and concepts by translating sensory appeals into images and metaphors. Translating sensory images into mental concepts has been attempted in previous studies as an auxiliary means of confirming concepts susceptible to imagery (Creswell, 1998; Weiss, 1992). However, the application of such imagery-based techniques has confined itself mostly to deriving consumers' mental concepts of certain objects or events (Creswell, 1998; Zaltman and Coulter, 1995), with very few studies attempting to derive marketing implications. Study 2 strives to bridge this gap by attempting to extract core sensory concepts associated with a specific coffee brand to find strategic or practical implications for sensory branding. Methodologically, this research examines how coffeerelated sensory preferences influence brand attitude through the use of pictures or images associated with the specific brand.
In sum, the results of these two studies may contribute to deepening our understanding of how sensory stimuli bring up resident memory, either experiential or imaginary, through self-referencing and positive affect. Moreover, based on a case approach, it may extract core sensory concepts by means of metaphoric images represented in semantic schema, which has rich implications for a creative strategy applicable to product-specific or brand-specific communications.

\section{Study 1: Theoretical background and development of hypotheses}

Five senses help us understand the world through recall of the resident information stored in our memories. Therefore, sensory systems play an important role in encoding, retrieving, and reconstructing information. Senses interact with memories differently, depending on individuals' social backgrounds and cultural differences. For example, researchers have investigated the role of scent as an external clue. Pleasant ambient scent improves both recall and recognition of unfamiliar brands rather than familiar brands (Morrin and Ratneshwar, 2000). It carries out the function of memory marker by strengthening the clarity of the recollection. Some scents, such as lemon, make people nervous and improve their information processing capability. Such information is useful for firms to develop marketing plans germane to sensory appeals in brand communications. The past literature on brand effectiveness has investigated, in addition to sensory appeals, national culture (Kim et al., 2008), ad model (Chung and Lee, 2008), in-store music (Ki and Lee, 2006), luxury products (Kim et al., 2010), and product type (Moon et al., 2010) as potential factors affecting brand equity and purchasing behavior.

This research proposes that response to sensory appeals invokes self-referencing and affective reaction, which in turn influence brand attitude. In other words, Study 1 examines the mediating effects of self-referencing and positive affect between sensory preference and brand attitude, while also exploring how multisensory appeals based on synaesthetic assumptions influence brand attitude using the five senses.

\subsection{The mediating effects of self-referencing}

In traditional consumer behavior and psychology research, selfreferencing increases elaboration, influences persuasion, and improves recall of words and sentences (Belleza, 1984; Klein and Loftus, 1988; Rogers et al., 1977). Self-referencing is "a process inducing relative significance where a consumer relates message information to his or her self experience or expectation" (Burnkrant and Unnava, 1989, p.632). The desirability of self-improvement motivates consumers to associate themselves with advertising situations in which the ad message evokes an ideal consumer self. Such an association connects consumers to a cognitive activity they can associate with themselves, thereby affecting their ad and brand attitudes. For example, Escalas (2004) reports that a mental simulation of wearing running shoes leads to a favorable attitude that, in turn, increases the likelihood to try and purchase that product. Self-referencing caused by mental simulation typically generates a positive emotion, while non-self-referencing generates skepticism or ignorance (Escalas, 2004). Chang (2005) claims that self-referencing and positive affect act as mediators between self-congruency and ad attitude. In other words, self-congruent ads generate positive affective reaction through self-referencing when consumers imagine that the ad image is congruent with their ideal self schemata.

How, then, does a consumer's preference toward sensory clues influence brand attitude formation through self-referencing? In general, when consumers see ad messages with sensory appeals, they first retrieve information registered in the schema which is built by past sensory experience (e.g., product color or background music). This retrieval helps them evaluate whether or not it is a favorable sense. 
For example, when consumers see a taste appeal ad message for a fresh-tasting orange, the ad image will be readily congruent with their ideal product or brand objective (e.g., a fresh-tasting orange) if they have a high level of favorability toward their taste sense. In addition, self-referencing through mental simulation (i.e., imagining eating an orange) can become more detailed and strengthened. This positive result of self-referencing affects a positive attitude toward ads and brands.

Therefore, self-referencing may act as a mediating variable between sensory preference and brand attitude, which leads to the first hypothesis.

H1. Consumer preference toward sensory clues in ads influences brand attitude through self-referencing of sensory information.

\subsection{The mediating effects of positive affect}

Both strength and preference of creative appeals can influence affective reaction toward ads. When consumers are exposed to stimuli, they compare sensory and physical characteristics with schema represented in memory. In this case, the affective tag causes a relevant affective reaction by acting as part of the schema (Hoffman, 1986). Positive affect is inducible without cognitive efforts when stimuli are congruent with sensory-involved schema. This view is consistent with the perspective of classical conditioning theory on affective reaction.

Ads should provide emotional benefits in order to build brand identity and enhance brand equity (Gurhan-Canlil and Ahluwalia, 1999; Ligas and Cotte, 1999). Kamp and Macinnis (1995) suggested brand connection, congruency between self and brand image, and strong positive feeling as prerequisite conditions to make an emotional connection with a brand. As noted above, when consumers are exposed to stimuli, they compare those stimuli with preferred schema represented in memory. Affective reaction is generated and sensory involvement is increased when the stimuli are congruent with the preferred schema and positive affect can be easily induced without cognitive efforts.

When the reaction to a particular sensory clue is emotionally intense (i.e., hilarious, jaunty) in TV commercials, consumers can form brand attitudes consistent with brand objectives even without making substantial cognitive efforts. For example, when consumers watch the TV commercial featuring fresh-tasting toothpaste, they easily situate themselves into the ad and are emotionally assimilated with it if they are highly involved in a fresh taste. Accordingly, they form a positive relationship between self and brand by transforming themselves through vicarious learning. In other words, consumers generate positive affect more easily when they have a preference toward sensory ad appeals; this positive effect, in turn, affects their ad and brand attitudes.

Therefore, affective reaction acts as a mediating variable between sensory preference and brand attitude.

H2. Consumer preference toward sensory clue in ads influences brand attitude through positive affect toward sensory information.

\subsection{Multisensory appeals and brand attitude}

What, then, is the role of the senses in the consumer decisionmaking process? The traditional decision-making process model is based on the idea that consumers are rational and that they reason consciously with perfect cognition. However, Hill (2003) argues that in past marketing efforts, many have overestimated the power of reason. That is, consumers are intuitive and use an unconscious process based on limited knowledge when they make a decision. In other words, Hill has proposed a new sensory cognitive theory that consumers sense first, then feel or think, and finally act, rather than taking the traditional process of learn-feel-act as an order of response toward stimuli. According to this new cognitive theory, the body should not be considered separate from the mind. Unconscious and sensory-emotional responses play an important role in defining the consumer-product relationship, interpreting advertising, and influencing products and services. This view broadens the boundaries of existing theory, which posits that consumers get product information through sensory information and reach purchasing behavior through the process of learn-feel. Additionally, sensory clues themselves can influence brand attitudes. In other words, sensory information may shift to brand information before changing into cognitive or emotional information.

What can we learn about the roles of the senses in branding? Based on research undertaken in twelve countries, Brown and Lindstrom (2005) developed "Sensagram," a more holistic five-sense dimensional approach, to help calculate the dynamics of the interplay between the senses, and found that a multisensory experience directly affects the perception of product quality and brand value. In addition, the number of senses activated in a brand is significantly related to the price of the product, so that brands appealing to all five senses can demand a higher price than those appealing to only one or two senses.

In identifying characteristics of synaesthesia, understanding multisensory experience with experiential brands is important. Stimulating one sensory modality produces an involuntary perception in another sense, and one or more sensory modalities become linked. For example, listening to music or sounds can be transferred to senses of color, taste, or touch; visual imagery can be experienced with sound or taste imagery; and so on (Cooper and Braithwaite, 2002). This sensory mechanism, called synaesthesia (syn + aesthesia= experiencing together), is pertinent to studying the role of sensory ad tactics at the heart of this research, since many ads use sensory appeals that are intended to create a synthetic ad attitude leading to a favorable brand attitude. This synthetic integration of sensory stimuli proves effective in enhancing a brand (Cooper and Braithwaite, 2002; Lindstrom, 2005). Thus, an understanding of synaesthesia can be applied to brand strategy, brand positioning, CRM, or new product development, and marketers should be able to define consumers' desirability and experience, identify sensory modalities to differentiate, and find ideal experiential brands by using the concept. The importance of senses in branding also can be seen in studies of personal long-term feelings, consumers' creative images, daydreaming, or ethnography. Experiential brands can develop long-term brand value and differentiate themselves from competing brands (Fournier, 1998).

Studies on sensory and experiential branding report that sensory experience directly provides information for brand attitude. Therefore, this research proposes that the five senses influence brand attitude and purchasing behavior and test the presence of synaesthetic functionality.

H3a. Positive relationships exist among the multisensory appeals of coffee brand ads based on synaesthetic assumptions.

H3b. Multisensory appeals used in coffee brand ads have a positive relationship with brand attitude.

\section{Study 1: method}

\subsection{Pretest}

For Study 1, a pretest showed which ad was associated with one core sensory appeal in order to control consistency and salience of ad copy. This was because ads encompassing multisensory appeals do not represent one salient sense well. The study used print ads rather than TV commercials because the latter, due to a variety of themes and expressions of stimuli used, are hard to manipulate for extracting one 
core sensory concept. With the print ads, respondents could easily evaluate the strength and meaning of sensory appeals.

A total of fifty participants in an undergraduate marketing class were recruited for the pretest. First, they were placed into five groups of ten and each group was assigned to select two ads representing a specific sensory appeal (for example, Group $1=$ visual, Group $2=$ olfactory, Group 3=palate, Group 4=tactile, Group 5=auditory). Each participant of a group was asked to bring ten ads and rate the degree of each sensory appeal in them. Out of 100 ads collected per group, two were selected to represent each sensory appeal, leaving a total of ten ads chosen from the five sensory groups.

Next, the ten selected print ads were scanned and converted into files and presented onscreen in the classroom. All pretest participants were instructed to view the ads and, using a 5-point Likert-type scale, rate the extent to which each was associated with the five senses. Visual ads were used rather than copy ads because of the possible transference effect through self-referencing associated with ad copy. Finally, using composite scores, five ads were selected that represented each sensory element: Windsor whisky for visual, Pioneer for auditory, 7-Up for the palate, Richville coffee for olfactory, and Clinique hair care system for tactile.

Out of those five ads, one was chosen which had the largest standard deviation between ratings to ensure the salience of one core sensory appeal. Consequently, the order of sensory elements in a visual coffee ad was olfactory (4.7), palate (4.0), visual (2.5), tactile (1.5), and auditory (.42) with a standard deviation of 4.27 . Thus, the coffee brand ad representing the olfactory sensory stimulus was selected for Study 1.

\subsection{Participants}

A total of 249 participants-120 males ( $48 \%$ ) and 129 females (52\%) in undergraduate marketing classes from universities in Seoul and Suwon were recruited to participate in the experiment. Student subjects were appropriate for this research in that people with college degrees are among the most affluent consumers of coffee in South Korea. Furthermore, college students are relatively homogeneous in terms of respondents' demographic and socioeconomic backgrounds.

This sampling frame to achieve homogeneity in participants' backgrounds was seen as ensuring the sample's internal validity without greatly damaging the external validity of its framing, due to the fact that coffee is a rather age-neutral product favored not only by the college student age group. Moreover, using a relatively homogeneous group such as college students can help reduce random error that might occur in a heterogeneous sample (Calder et al., 1982). As for age, most students (98\%) indicated they were between 20 and 29.

\subsection{Procedure and Measures}

Each participant received a questionnaire packet with ad stimuli and provided a response after each ad. In consideration of the time needed for self-referencing, ad stimuli were included in the questionnaire in order to give subjects a little more time to respond. Before starting the experiment, subjects were told that the purpose of this research was to evaluate a trial version of a new ad for a "premium hazelnut coffee brand."

Subjects were instructed to relate the situations or stimuli presented in the ads to their own experiences. As a control sensory clue, a visual with an olfactory stimulus obtained the highest score from the pretest. This visual pictured a man savoring the smell of coffee, which was depicted in a shimmering haze. The ad copy read, "I smell the delicate aroma of hazelnut coffee." The main purpose of Study 1 was to examine whether self-referencing and positive affect play a role as mediators between preferences toward a core sensory appeal used in ads and brand attitude. For this purpose, the subjects were instructed to respond to questions that measured self- referencing, positive effect, and brand attitude toward the coffee brand after they were exposed toads containing visual and copy message to stimulate the olfactory sensory clue. Three different versions of the ad stimuli were shown to study participants, with Type A showing only ad copy, Type B showing only visual, and Type C showing both copy and visual. Subsequently, participants were asked to rate the extent of self-referencing, positive effect, preference for sensory appeal, and brand attitude. All items were measured on 7point Likert-type scales.

The scale for sensory self-referencing was adapted from that of Debevec and Iyer (1988). The four-item scale measured the extent to which respondents (1) pictured themselves in an ad, (2) pictured themselves in the position of persons in the ads, (3) identified with similar events in life experiences, and (4) identified with the persons in the ads. Edell and Burke's (1987) scale on emotion was used to measure positive affect; the five items were (1) delighted, (2) good, (3) excited, (4) moved, and (5) warm-hearted. Three items by Holbrook and Batra (1987) were used to measure brand attitude: likeability, favorability, and delightfulness. The survey used hazelnut premium coffee as a brand name for the ad rather than an existing brand name. The construct of sensory preference toward the smell of coffee was operationalized by asking, "How much do you like the smell of hazelnut coffee?"

\subsection{Analysis Results}

In order to test $\mathrm{H} 1$ regarding the mediating effects of selfreferencing on the relationship between sensory preference and brand attitude, the researchers adopted the determinant conditions for the presence of mediating effect proposed by Baron and Kenny (1986). According to these conditions, for the mediating effect to be corroborated, the predictor variable's regression coefficient must be bigger than the same predictor's estimate obtained when the predictor variable is entered into the regression model along with the mediator variable. Multiple regression analyses were performed with a view to confirming the mediating effects of self-referencing and positive affect using different advertising platforms (copy only, visual only, and copy and visual combined).

The analysis on self-referencing revealed that it has a significant mediation effect, since the sensory preference variable's beta coefficient was reduced in all three platform types when the selfreferencing effect was constrained in the full regression model, as shown in Table $1(\mathrm{a}>\mathrm{b})$. In particular, the reduction rate calculated by $(a-b) / a$ was most salient for the visual only platform $(27.77 \%)$, followed by copy and visual (26.85\%) and copy only (8.62\%). This result confirms the hypothesis that the intensity of self-referencing experienced by subjects while processing an ad determines the effect of sensory preference on brand attitude.

Next, multiple regression analyses were performed to test $\mathrm{H} 2$ regarding the mediating effects of positive effect on the relationship between sensory preference and brand attitude. As with selfreferencing, positive affect had a positive mediating effect on all three ad platforms; its beta estimate decreased in the full model, including sensory preference and positive affect as predictor variables (see Table 2). The biggest beta reduction occurred in the visual only platform (33.33\%), followed by copy and visual (32.76\%) and copy only (23.64\%). Thus, H2 was supported.

To test H3a, which proposed correlations among the multisensory appeals based on the synaesthesia assumption, subjects were asked to rate the importance of sensory appeals in choosing a hazelnut coffee brand. The rating system used was a composite rating in which the total score added up to 10 . The results of the correlation analysis revealed that most of the sensory appeals showed negative correlations, except that between auditory and tactile appeals. This signifies that in coffee brand choice, sensory appeals do not show a correlational (synaesthetic) characteristic. The most important sensory 
Table 1

Verification of mediation effects of self-referencing.

\begin{tabular}{|c|c|c|c|c|c|c|c|}
\hline \multirow[t]{2}{*}{ Predictor } & \multirow[t]{2}{*}{ Criterion } & \multicolumn{2}{|c|}{ Copy only } & \multicolumn{2}{|c|}{ Visual only } & \multicolumn{2}{|c|}{ Copy and visual } \\
\hline & & beta & $\mathrm{t}$ & beta & $\mathrm{t}$ & beta & $\mathrm{t}$ \\
\hline Sensory preference & Self-referencing & .172 & $1.938^{*}$ & .221 & $2.500^{*}$ & .326 & $3.821^{* *}$ \\
\hline Sensory preference & Brand attitude & ${ }^{\mathrm{a}} .406$ & $4.934^{* *}$ & ${ }^{\mathrm{a}} .126$ & $1.400^{*}$ & a .406 & $4.934^{* *}$ \\
\hline Self-referencing & Brand attitude & .270 & $3.107^{* * *}$ & .178 & $1.994^{*}$ & .432 & $5.320^{* *}$ \\
\hline Sensory preference & Brand attitude & b.371 & $4.531^{* *}$ & ${ }^{\mathrm{b}} .091$ & .996 & b.297 & $3.621^{* *}$ \\
\hline Self-referencing & & .206 & $2.514^{*}$ & .158 & 1.725 & .336 & $4.092^{* *}$ \\
\hline Beta reduction rate & & \multicolumn{2}{|c|}{$8.62 \%$} & \multicolumn{2}{|c|}{$27.77 \%$} & \multicolumn{2}{|c|}{$26.85 \%$} \\
\hline
\end{tabular}

${ }^{*}$ Significant at .10 level, ${ }^{* *}$ significant at .05 level, ${ }^{* * *}$ significant at .01 level.

element in choosing a coffee brand was palate (3.69), followed by olfactory (3.29), visual (1.41), tactile (.63), and auditory (.42). ANOVA confirmed a significant difference among the five senses $(F=469.191$. $\mathrm{p}=.000)$.

Next, H3b, which proposes the effects of sensory appeals on attitudes toward advertising and brands, was tested by regression analyses, the results of which (see Table 3 ) indicate that olfactory (beta $=.155, \mathrm{t}=2.428$ ) and auditory (beta $=.125, \mathrm{t}=1.848$ ) senses were influential on brand attitude at .05 and .01 significance levels, respectively. On the other hand, palate negatively affected attitude toward advertising in the copy-only and copy-and-visual ad formats. An interesting finding is that there are disjoint patterns in terms of sensory factors affecting brand attitude as opposed to ad attitude. For instance, olfactory and auditory senses are salient in the former but not for the latter, whereas palate is significant for ad attitude but not for brand attitude. In terms of their impact on attitudes toward ad versus brand, the difference between the sensory appeals suggests how they differently affect the way people perceive attitudes toward ads and brands, and thus should be used for discrete purposes. It remains to be studied further whether the differences in their influence are due to the product category (i.e., coffee), which accounts for the differences in product-related sensory preferences (Lindstrom, 2005).

\section{Study 2: eliciting core sensory concepts}

Study 1 focused on understanding the relationship between sensory preference and brand attitude, based on subjects' ability to retrieve stored images using their internalized experiences with particular sensory stimuli. For instance, when a person who has a high preference toward palate is exposed to an ad for a product's taste appeal in a survey, that person would readily identify with the product's intended use, creating a positive ad attitude by means of self-referencing resulting from mental simulation. However, this approach may be construed as researcher-centered because it relies on a questionnaire-based method that makes it difficult to explore in depth how research subjects process and mentally arrive at self- referenced conclusions. In addition, Study 1 was primarily concerned with how ads affect attitude toward a generic (hazelnut) coffee brand, which is devoid of brand-specific image elicitation. To overcome these shortcomings, the goal of Study 2 was to elicit image-based information from the research subjects and integrate it into a broader research perspective by means of qualitative methods. For this purpose, the study used a specialty coffee brand, "The Coffee Bean \& Tea Leaf," to apply some of the qualitative techniques such as ZMET and association of core concepts based on representative sensory images.

\subsection{Conceptual frame of ZMET}

According to Zaltman and Coulter (1995), most human thoughts are composed of images, and about $80 \%$ of human communication is non-verbal. Therefore, they assert, it is important to be able to interpret the thoughts expressed in non-verbal form, which facilitates the grasp of consumers' deep inner needs. The essence of metaphor lies in appreciating and experiencing an object from diverse viewpoints, making it possible to successfully develop products or services in the market. Thus, understanding product-specific metaphors allows researchers to develop more creative advertising or promotional materials that appeal to consumers' mental imagery.

How does image-based metaphor relate to this research, which centers on sensory appeals? Zaltman and Coulter (1995) contend that human senses are quick to pick up crucial metaphoric clues. They argue that senses act like doors to our minds where new information can enter, and all thoughts and ideas are derived from the surface stimulus experiences that dictate our bodily movements. This premise suggests that sensory metaphor may act as a means by which to understand consumer thoughts and actions. Most of the metaphors are mental images, and the majority of those are visual. Consumers can use pictures, such as drawings or illustrations from magazines or newspapers, to convey their visual metaphors. Pictures in particular are a natural and efficient way to explore consumers' inner concepts and extract constructs that are rich in semantic abstractions (Creswell, 1998; Weiss, 1992).

Table 2

Verification of mediation effects of positive affect.

\begin{tabular}{|c|c|c|c|c|c|c|c|}
\hline \multirow[t]{2}{*}{ Predictor } & \multirow[t]{2}{*}{ Criterion } & \multicolumn{2}{|c|}{ Copy only } & \multicolumn{2}{|c|}{ Visual only } & \multicolumn{2}{|c|}{ Copy and visual } \\
\hline & & beta & $\mathrm{t}$ & beta & $\mathrm{t}$ & beta & $\mathrm{t}$ \\
\hline Sensory preference & Positive affect & .231 & $2.635^{* *}$ & .134 & 1.490 & .256 & $2.931^{* *}$ \\
\hline Sensory preference & Brand attitude & ${ }^{\mathrm{a}} .406$ & $4.934^{* *}$ & .126 & 1.400 & .406 & $4.934^{* *}$ \\
\hline Positive affect & Brand attitude & .488 & $6.202^{* *}$ & .322 & $3.762^{* *}$ & .592 & $8.146^{* *}$ \\
\hline Sensory preference & Brand attitude & ${ }^{\mathrm{b}} .310$ & $4.071^{* *}$ & .084 & .937 & .273 & $3.829^{* *}$ \\
\hline Positive affect & & .416 & $5.464^{* *}$ & .311 & $3.598^{* *}$ & .522 & $7.323^{* *}$ \\
\hline Beta reduction rate & & \multicolumn{2}{|c|}{$23.64 \%$} & \multicolumn{2}{|c|}{$33.33 \%$} & \multicolumn{2}{|c|}{$32.76 \%$} \\
\hline
\end{tabular}

*Significant at .10 level, ${ }^{* *}$ significant at .05 level, ${ }^{* * *}$ significant at .01 level. 
Table 3

Effects of sensory appeals on brand and ad attitudes.

\begin{tabular}{lclcl}
\hline \multirow{2}{*}{$\begin{array}{l}\text { Independent } \\
\text { variable }\end{array}$} & $\begin{array}{l}\text { Brand } \\
\text { attitude }\end{array}$ & \multicolumn{2}{l}{ Ad attitude } & \\
\cline { 3 - 5 } \cline { 3 - 4 } & & Copy only & Visual only & Copy and visual \\
\hline Olfactory & $.155^{* *}$ & -.069 & .086 & -.015 \\
Palate & -.086 & $-.323^{* * *}$ & -.040 & $-.163^{*}$ \\
Visual & -.095 & .007 & -.111 & -.111 \\
Tactile & -.029 & -.151 & .031 & -.135 \\
Auditory & $.125^{*}$ & .013 & .036 & .056 \\
\hline
\end{tabular}

${ }^{*}$ Significant at .10 level, ${ }^{* *}$ significant at .05 level, ${ }^{* * *}$ significant at .01 level.

\subsection{Research design}

For this part of the research, sixteen university students reported themselves as high in coffee preference, thus qualifying as research subjects because of their prior knowledge of and experience with coffee consumption. Based on brand awareness of "The Coffee Bean \& Tea Leaf" (hereinafter referred to as "Coffee Bean"), twelve students were selected to participate in personal in-depth interviews and were given specific instructions regarding research participation through in-person and e-mail communications. The reason Coffee Bean was chosen is that it garnered a very favorable brand image in Korea, centering on high values regarding price and a unique taste quality that set it apart from competitors such as Starbucks.

First, participants were asked to bring materials that best represented what Coffee Bean meant to them by taking photos themselves or from books, magazines, newspapers, and other sources. They were given one week to do this, and were individually scheduled for personal in-depth interviews. Next, the researchers asked the participants to describe core concepts representing five sensory appeals associated with Coffee Bean, then used data to analyze the effects of sensory images on brand attitudes. The data collected from this procedure was to enable the researchers to understand how the participants' subjective, abstract thoughts associated with sensory inputs translated into mental concepts toward the coffee brand.

\subsection{Findings}

According to Zaltman and Coulter (1995), in order to discover summarized image categories representing values or dimensions that lead to participants' mental maps, research needs to explore themes and constructs embedded in the responses. These themes and constructs were used primarily as the basis for qualitative methods (categorization, categorical classification, comparison of occurrences, and dimensionalization). Table 4 shows the results of interviews based on six participants who marked "high" on their preference for Coffee Bean and gave researchers reasons for bringing specific image materials (i.e., pictures) regarding the brand.

Of the eleven presented images, six were based on tangible objects (bowl of beans, tree leaves, cake, wooden table, perfume, and table) and five were of people (trendy woman, three Korean movie stars, modern-looking woman). When sensory classification was applied to the reasons for having chosen particular images, there were seven visual clues and three olfactory clues. Another interesting finding is that a person-based metaphor was evoked for the brand. For example, Informant $\mathrm{B}$ chose a picture of a foreign female invoking the image of a vain woman. Informant F likened Coffee Bean to a "noble woman" who is found solely in big cities. In contrast to these images, the reasons given for object-based images suggested sensory substances. In particular, the olfactory sense (sweet aroma, stand-alone scent, coffee shop aroma) was predominant. As for visual images, those constructs representing the Coffee Bean logo, such as brown or bean, were cited, along with some characteristic images of the shop's patrons such as "fashionable customers" and "only found in big cities."

Finally, the participants were asked to write core sensory concepts associated with Coffee Bean and rank-order them in terms of the impact they had on brand attitude. As suggested by Zaltman and Coulter (1995), the elicitation of core sensory concepts is intended to discover common (or homogeneous) traits associated with those concepts. Table 5 shows results.

The ranked influences of core sensory concepts on brand attitude reveals that visual had the biggest impact (average rank $=1.33$ ), followed by palate (2.66), olfactory (3.08), auditory (3.58), and tactile (4.41). This result departs slightly from the findings for H3a in Study 1, which rank-ordered five sensory appeals in terms of their importance in selecting a coffee brand (in order: palate, olfactory, visual, tactile,

Table 4

Images associated with "Coffee Bean" and the reasons for the images.

\begin{tabular}{|c|c|c|}
\hline Informant & Presented images & Reasons for images \\
\hline A (female, 24) & $\begin{array}{l}\text {-Bowl containing beans } \\
\text {-Leaves }\end{array}$ & $\begin{array}{l}\text { "It is a symbolic picture representing [Coffee Bean]'s logo." } \\
\text { "The shop's brownish interior reminds me of autumn." }\end{array}$ \\
\hline B (female, 23) & $\begin{array}{l}\text {-Cake, } \\
\text {-Brown colored wooden table } \\
\text {-Perfume } \\
\text {-Trendy foreign female }\end{array}$ & $\begin{array}{l}\text { "I really loved the cake my sister bought me from the brand shop" } \\
\text { "It is similar to the brown image of [Coffee Bean]." } \\
\text { "It reminds me of the aroma at the shop entrance." } \\
\text { "It reminds me of woman driven by vanity." }\end{array}$ \\
\hline C (male,25) & Tree with brown leaves against sunset & $\begin{array}{l}\text { "It is like [Coffee Bean]'s table and chair." } \\
\text { "It evokes a sweet aroma scent." } \\
\text { "I think beans are coffee nuts." } \\
\text { "I feel the warmth of the shop basking in sunset light." } \\
\text { "The brown logo of the shop matches the tree." }\end{array}$ \\
\hline D (male, 22) & $\begin{array}{l}\text { Two Korean movie stars featured in a } \\
\text { coffee ad for Maxim }\end{array}$ & $\begin{array}{l}\text { "The ad's background is autumn, as with the [Coffee Bean]." } \\
\text { "[Coffee Bean]'s scent lacks emotion, and it stands alone." } \\
\text { "[Coffee Bean] is like my friend." } \\
\text { "[Coffee Bean]'s coffee is too expensive compared to Maxim's." }\end{array}$ \\
\hline $\mathrm{E}$ (male, 23) & Smiling face of a Korean movie star & $\begin{array}{l}\text { "I kind of hate the star because he is so admired by women." } \\
\text { "Women I know never drink cheap coffee from vending machines." }\end{array}$ \\
\hline $\mathrm{F}$ (female 23) & Foreign female of modern look & $\begin{array}{l}\text { "[Coffee Bean] is a noble woman. It can only be found in bustling big cities." } \\
\text { "[Coffee Bean] is arrogant." } \\
\text { "The store patrons are all fashionable. They look cool wearing sunglasses } \\
\text { or carrying notebook computers." }\end{array}$ \\
\hline
\end{tabular}


Table 5

Core sensory concepts and the ranked influence on brand attitude.

\begin{tabular}{|c|c|c|c|c|c|c|c|c|c|c|}
\hline & Visual & & Auditory & & Olfactory & & Palate & & Tactile & \\
\hline A & Social meeting & 1 & Coffee dripping & 4 & Cool scent & 2 & Smooth & 3 & Heavy timber & 1 \\
\hline B & Luxury & 2 & Jazz & 4 & Fragrance & 5 & Sweet & 1 & Comfortable & 3 \\
\hline $\mathrm{C}$ & Leisurely people & 2 & Bossanova music & 3 & Sweet aroma & 4 & Sweet flavor & 1 & Downy & 5 \\
\hline $\mathrm{D}$ & Brown color & 1 & Pop music & 4 & Sweet scent & 3 & Sweet flavor & 3 & Velvet sofa & 5 \\
\hline $\mathrm{E}$ & Brand logo & 3 & Bell sound & 2 & Tree smell & 1 & Rice water smell & 4 & Bed sheet & 5 \\
\hline $\mathrm{F}$ & Coffee Bean logo & 1 & Coffee dripping & 3 & Sweetness & 2 & Caramel & 2 & Paper cup & 5 \\
\hline G & Autumn weather & 1 & Bossanova & 2 & Faint aroma & 3 & Smooth & 5 & Coziness & 4 \\
\hline $\mathrm{H}$ & Brown color & 1 & Jazz & 4 & Coffee bean & 3 & Rich flavor & 2 & Snugness & 5 \\
\hline I & Brown interior & 1 & Hubbub & 4 & Rich smell & 3 & Smoothness & 2 & Wood grain & 5 \\
\hline $\mathrm{J}$ & Red lipstick & 1 & Classic music & 5 & Fragrant smell & 4 & Macchiato & 2 & Velvet sofa & 3 \\
\hline $\mathrm{K}$ & Curvy shape & 1 & Quiet cello & 4 & Bitter smell & 5 & Bitter taste & 4 & Warmth & 3 \\
\hline $\mathrm{L}$ & Brown color & 1 & Singing voice & 4 & Coffee aroma & 2 & Sweetness & 3 & Warmth & 5 \\
\hline Ave. rank & 1.33 & & 3.58 & & 3.08 & & 2.66 & & 4.41 & \\
\hline
\end{tabular}

* The number next to each concept indicates the rank of the extent to which each sensory element affects brand attitude (i.e., $1=$ most influential, $5=$ least influential).

and auditory). This result suggests that salient sensory concepts associated with a particular coffee brand (such as Coffee Bean) differ from sensory appeals that are used in selecting a brand.

In the case of Coffee Bean, visual concepts were the most influential, predominantly represented by a brown color (mentioned four times) and brand logo (mentioned three times). This finding reaffirms that the brand's logo and interior color play an important role in forming brand attitude. Another interesting finding is that the "sweetness" concept was mentioned four times for palate-related concepts and three times for olfactory concepts. This finding possibly indicates that sweetness may act as an agent to link the two sensory concepts of taste and smell, which somehow supports the theoretical views of the synaesthetic paradigm.

\section{Discussion, implications, and future research directions}

Based on the sensory information processing theory, this research set out to investigate the effects of sensory preferences on attitudes toward a coffee brand with the aim of corroborating the mediating effects of self-referencing and positive affect. Another important objective here was to verify the role of sensory appeals' metaphoric images in forming brand attitude by means of eliciting sensory concepts on a coffee brand based on qualitative methods. The research found the following. First, in the case of coffee advertising, self-referencing and positive affect are significant mediators between the sensory clue preference and brand attitude. Especially noteworthy is that the ad with only a visual element showed much more mediating effect than ads with copy only or copy and visual together. The discovery that sensory preference helps maximize ad effectiveness by adopting particular delivery platforms sheds important insights on formulating creative strategies for sensory ads. In addition, the finding that sensory appeals had disparate effects on brand attitude as opposed to ad attitude may invoke useful strategic thinking because it indicates the need to use sensory appeals differently depending on the goals of advertising or brand effectiveness.

In Study 2, which took a qualitative approach, the "Coffee Bean" brand elicited core sensory concepts based on metaphoric imagery analysis using ZMET. The sensory appeals that most affected attitude toward the brand were, in terms of importance, visual, palate-related, olfactory, auditory, and tactile, reconfirming the importance of the visual element in eliciting the brand attitude. Another significant finding was that "sweetness" is a common trait (concept) that links olfactory and palate-related senses together. This result reveals some new aspects of synaesthetic conceptual traits associated with the Coffee Bean brand, which suggests the usefulness of taking a qualitative approach based on a metaphor-eliciting method. In line with the importance of synaesthetics that the literature reports, this research supports the presence of synaesthetic traits in sensory image-based metaphors about a coffee brand. This revelation suggests the need for advertisers to understand which sensory stimuli blend together to create maximum synergistic effects on brand attitude. Understanding this synergistic mechanism may be particularly useful in formulating copy or visual tactics designed to enhance advertising effectiveness and may, depending on the magnitude of the synergistic effects, boost brand equity.

Future studies can benefit from using more than one brand to enable direct comparisons among different brands of the same product categories. A better but more comprehensive approach would be to employ more than one product category to compare the effects of sensory appeals on brand and ad attitudes. The result of such an approach would help researchers formulate product-specific sensory branding strategies, which would broaden our knowledge of product-based sensory branding.

One more reason for the need to add different product categories is the fact that coffee as a product holding a dominant association with one sense (i.e., olfactory) may cause some spill-over effect that could undermine research subjects' ability to combine and synthesize other less salient sensory appeals designed to create a sensory-based overall impression. As a way to address this concern, future researchers are advised to consider other product categories that elicit more than one dominant sense.

Finally, the hybrid use of quantitative-qualitative techniques proved its worth for complementary utility. Especially worthwhile is the hybrid approach's ability to generate in-depth interpretations of the phenomenon in question. As this research intended to combine a case approach with experimental study using sensory appeals as a base for comparing different aspects of their effects, the result is limited in generalizing beyond the brand used for the case approach. Therefore, future studies may benefit by converging the research focus on the same aspects of sensory effects using different brands. In addition, more studies need to be done to attempt qualitative techniques enabling deeper interpretations. For instance, laddering techniques such as means-end chain models or thematic apperception tests are recommended. This would allow participants to talk about the images or illustrations presented so that researchers could make an inference on the hierarchically motivated or subliminal perceptions of the sensory appeals.

\section{Acknowledgements}

The authors thank Stanford A. Westjohn of the University of Toledo and Jason Chan of Kyonggi University for their helpful comments on this paper. 
[Type A]

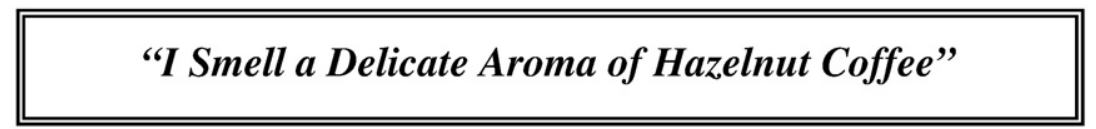

\section{[Type B]}

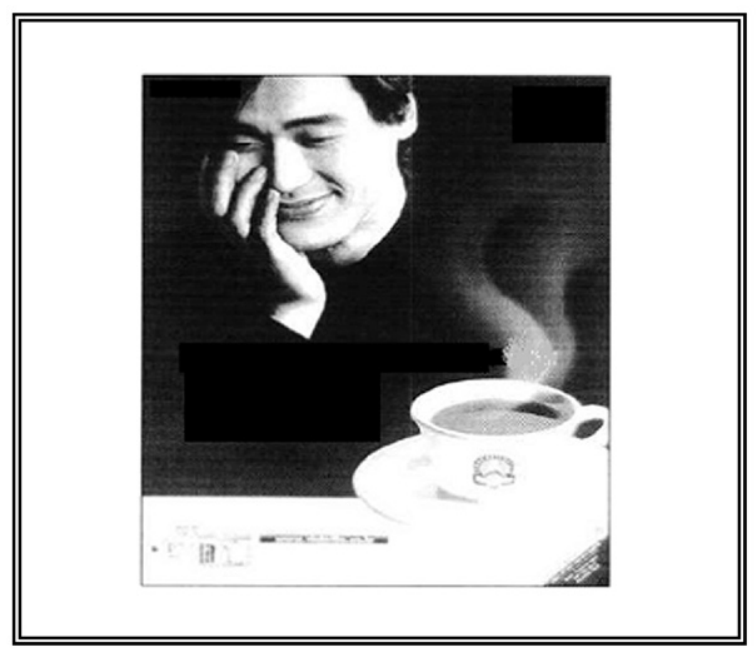

\section{[Type C]}

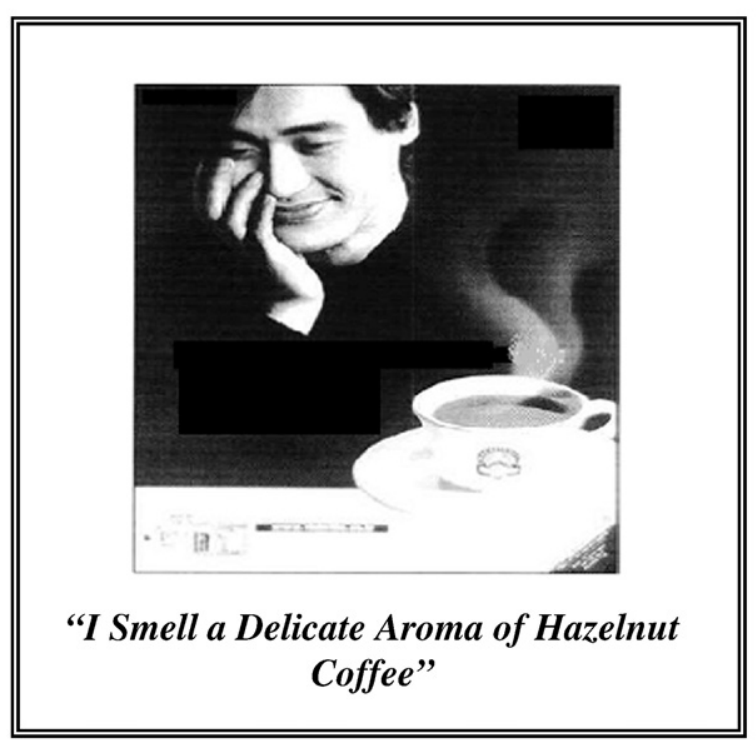

\section{References}

Baron RM, Kenny DA. The moderator-mediator variable distinction in social psychological research: conceptual, strategic, and statistical considerations. J Pers Soc Psychol 1986;51(6):1173-82.

Belleza FS. The self as mnemonic device: the role of internal cues. J Pers Soc Psychol 1984;47:506-16.

Brown M, Lindstrom M. Sensagram, a sensory program developed by Martin Lindstrom as commissioned by Millward Brown; 2005.

Burnkrant RE, Unnava HR. Self-referencing: a strategy for increasing processing of message content. Pers Soc Psychol Bull 1989;15:628-38.

Calder BJ, Phillips LW, Tybout AM. The concept of external validity. J Consum Res 1982;9(3):240-4.

Chang C. Ad-self -congruency effects: self-enhancing cognitive and affective mechanism. Psychol Mark 2005;22(11):887-910.

Chung JH, Lee SM. The effect of AD noises caused by AD model selection on brand awareness and brand attitudes. J Glob Acad Mark Sci 2008;18(3):205-17.

Cooper P, Braithwaite A. Synaesthesia: researching the power of sensation, paper presented at ESOMAR Worldwide Qualitative Research Conference, Boston; 2002.
Creswell JW. Qualitative inquiry and research design: choosing among five traditions. Sage; 1998

Debevec K, Iyer E. Self-referencing as a mediator of the effectiveness of sex-role portrayals in advertising. Psychol Mark 1988;5:71-84.

Edell JA, Burke MC. The power of feelings in understanding advertising effects. J Consum Res 1987;14:421-33.

Escalas JE. Imagine yourself in the product: mental simulation, narrative transportation, and persuasion. J Advert 2004;33(2):37-48.

Fournier S. Consumers and their brands: developing relationship theory in consumer research. J Consum Res 1998;24:343-73 March.

Gurhan-Canlil Z, Ahluwalia R. Cognitive and relational perspectives on brand equity. Adv Consum Res 1999;26:343-65.

Heiser RS, Sierra JJ, Torres IM. Creativity via cartoon spokespeople in print ads: capitalizing on the distinctiveness effect. J Advert 2008;37(4):75-84.

Hill D. Body of truth; Leveraging what consumers can't or won't say. Hoboken, N.J: John Wiley \& Sons; 2003.

Hoffman ML. Affect, cognition, and motivation. In: Sorrentino RM, Higgins T, editors. Handbook of motivation and cognition. NY: Guilford Press; 1986. p. 244-80.

Holbrook MB, Batra R. Assessing the role of emotions as mediators of consumer response to advertising. J Consum Res 1987;14:404-20. 
Kamp E, Macinnis DJ. Characteristics of portrayed emotions in commercials: when does what is shown in ads affect viewers? J Advert Res 1995;35(6):19-28.

Ki HM, Lee Y. Effect of atmospheric music and advertising photos on consumers emotional state and approach behavior in fashion stores. J Glob Acad Mark Sci 2006;16(3):203-15.

Kim KH, Ko EJ, Graham H, Nick Lee, Lee DH, Jung HS, et al. Brand equity and purchase intention in fashion products: a cross-cultural study in Asia and Europe. J Glob Acad Mark Sci 2008;18(4):245-76.

Kim KH, Park SY, Lee SH, Knight DK, Xu B, Jeon BJ Moon HI. Examining the relationships among attitude toward brands, customer equity, and customer lifetime value in a Korean context. J Glob Acad Mark Sci 2010;20(1):12-25.

Klein SB, Loftus J. The nature of self-referent encoding: the contributions of elaborative and organizational processes. J Pers Soc Psychol 1988;55:5-11.

Ligas M, Cotte J. The process of negotiating brand meaning: a symbolic interactionist perspective. Adv Consum Res 1999;26:609-14.
Lindstrom M. Brand Sense: Build Powerful Brands through Touch, Taste, Smell, Sight, and Sound. New York: Free Press; 2005.

Moon BJ, Park WK, Choi SC. Relationships among brand equity components: an exploratory study of the moderating role of product type. J Glob Acad Mark Sci 2010;20(1):34-50.

Morrin M, Ratneshwar S. Does it make sense to use scents to enhance brand memory? Adv Consum Res 2000;28:122-5.

O'Quin K, Besemer SP. The development, reliability, and validity of the revised creative product semantic scale. Creativity Res J 1989;2(4):267-78.

Rogers TB, Cuiper NA, Kirker WS. Self-reference and the encoding of persona information. J Pers Soc Psychol 1977;35:677-88.

Weiss RS. Learning from strangers: the art and method of qualitative interview studies. New York: Free Press; 1992.

Zaltman G, Coulter RH. Seeing the voice of the customer: metaphor-based advertising research. July/August] Advert Res 1995:35-51. 